\title{
A STUDY OF POST-OPERATIVE COMPLICATIONS OF THYROID SURGERY
}

\author{
P. Anbalagan'1, S. Manikannan², A. Mohammed Imran Khan ${ }^{3}$
}

${ }^{1}$ Assistant Professor, Department of General Surgery, Government Vellore Medical College and Hospital, Vellore. ${ }^{2}$ Assistant Professor, Department of General Surgery, Government Vellore Medical College and Hospital, Vellore. 3 Junior Resident, Department of General Surgery, Government Vellore Medical College and Hospital, Vellore.

\section{ABSTRACT}

\section{BACKGROUND}

The aims of the study are- 1. To compare complication rates of bilateral Sub-Total Thyroidectomy (SBT), Near Total Thyroidectomy (NTT), Hemithyroidectomy (total lobectomy and isthmusectomy) and Total Thyroidectomy (TT) in cohort of patients undergoing surgery for various thyroid disorders. 2. To compare complication rates after thyroidectomy for benign diseases and malignant diseases. To identify ways to avoid the post-operative complications.

\section{MATERIALS AND METHODS}

One hundred and seventeen patients who underwent thyroid surgery for various thyroid disorders at the Government Vellore Medical College Hospital, Vellore, Tamilnadu, India between January 2014 and January 2016 were studied. Operations were performed by various Professors, Assistant Professors and also by Surgical Post Graduates supervised by senior surgeons using various surgical techniques. Indications for surgery in this study group include forty-five patients with non-toxic Multinodular Goitre (MNG), twenty-two patients with toxic multinodular goitre, thirty-four patients with nontoxic solitary nodular goitre, thirteen patients with carcinoma, two patients with recurrent goitre and one patient with colloid goitre. Of these one hundred and seven patients were female and ten patients were male. These patients were broadly divided into two categories based on the diagnosis and treatment modality. For all selected patients, a thorough history was elicited followed by a complete physical examination. The basic biochemical and haematological investigations were done for all patients. It was decided to request special investigations like thyroid hormone profile and serum calcium estimation only in selected cases, where a disturbance in the functional status was suspected. Vocal cords were examined pre-operatively by indirect laryngoscope in all the patients, whereas post-operative vocal cord examination was performed only when hoarseness occurred. Patients were classified as having hypocalcaemia (Hyperparathyroidism) if both clinical and biochemical (A fall in corrected serum calcium concentration below 8 $\mathrm{mg} / \mathrm{dL}$ and/or the need for calcium supplementation), supportive evidence were present. FNAC was done for all patients. Based on the final diagnosis, the treatment was given as advised by the experts.

\section{RESULTS}

The following conclusions are drawn from this study. 1. This study shows that the total thyroidectomy or hemithyroidectomy can be done with very low complication rate in cases of benign thyroid disease affecting the whole gland. 2. Hypoparathyroidism, however, is a relatively common and significant complication than the recurrent laryngeal nerve injury after surgery for thyroid disorders. 3. Thyroid carcinoma, recurrent goitre, toxic goitre and total thyroidectomy are risk factors for post-operative complication. 4. Complication rates are similar for bilateral subtotal thyroidectomy and total thyroidectomy, and there is a risk of recurrence with bilateral subtotal thyroidectomy. Because total thyroidectomy carries a risk of complication similar to that for bilateral subtotal thyroidectomy, it is not logical to avoid total resections. Therefore, near total or total thyroidectomy may be the operation of choice for multinodular goitre. 5. Complications and sequelae of thyroid surgery can yet be reduced by careful evaluation of the surgical and medical therapeutic options have more precise surgical indications, a thorough knowledge of the surgical anatomy, a rigorous surgical technique, a systematic dissection of recurrent laryngeal nerve and parathyroid gland in case of bilateral operation and meticulousness during the procedure.

\section{CONCLUSION}

1. This study shows that the total thyroidectomy or hemithyroidectomy can be done with very low complication rate in cases of benign thyroid disease affecting the whole gland. 2. Hypoparathyroidism, however, is a relatively common and significant complication than the recurrent laryngeal nerve injury after surgery for thyroid disorders. 3. Thyroid carcinoma, recurrent goitre, toxic goitre and total thyroidectomy are risk factors for post-operative complication.

\section{KEYWORDS}

Sub-Total Thyroidectomy, Hemi-Thyroidectomy, Near Total Thyroidectomy, Multinodular Goitre.

HOW TO CITE THIS ARTICLE: Anbalagan P, Manikannan S, Khan AMI. A study of post-operative complications of thyroid surgery. J. Evolution Med. Dent. Sci. 2017;6(5):413-418, DOI: 10.14260/Jemds/2017/92

Financial or Other, Competing Interest: None.

Submission 05-12-2016, Peer Review 01-01-2017,

Acceptance 09-01-2017, Published 16-01-2017.

Corresponding Author:

Dr. P. Anbalagan,

Assistant Professor,

Department of General Surgery,

Government Vellore Medical College and

Hospital, Vellore.

E-mail: anbalagan_88chemco@yahoo.com

DOI: $10.14260 /$ jemds $/ 2017 / 92$

\section{BACKGROUND}

Thyroidectomy is a common operation with an extremely low mortality. ${ }^{1}$ It is associated with specific morbidities, which are related to the experience of the surgeon, however.2 Very low surgical morbidity rates for thyroidectomy are reported in specialised centres.

In competent hands, thyroid surgery is associated with few complications and no fatality. Post-operative complications may be as insignificant as oedema of the flap or as dangerous and life-threatening as haemorrhage or respiratory obstruction. The majority are avoidable with 
sound surgical technique and good preoperative preparation. With proper preoperative management, the patient will be euthyroid at the time of surgery. If the patient is hyperthyroid, laryngeal oedema may result producing respiratory obstruction. Careless technique may result in massive haemorrhage, recurrent laryngeal nerve paralysis or both causing respiratory embarrassment. Lack of experience or of attention to technical details may involve removal of too little or too much thyroid tissue or possibly all parathyroids resulting in myxoedema, recurrent hyperthyroidism or parathyroid deficiency.

Complication rates associated with thyroid surgery can be evaluated only through analysis of case studies and followup data.

The present study reports the clinical audit of thyroid surgery for adult patients undertaken at the Government Vellore Medical College Hospital, Vellore. The complications of thyroidectomy are highlighted and compared to publish data.

\section{Aims and Objectives}

1. The aim of the study is to compare complication rates of bilateral Sub-Total Thyroidectomy (SBT), Near Total Thyroidectomy (NTT), Hemithyroidectomy (Total lobectomy and isthmusectomy), and Total Thyroidectomy (TT) ${ }^{1}$ in cohort of patients undergoing surgery for various thyroid disorders.

2. To compare complication rates after thyroidectomy for benign diseases and malignant diseases.

3. To identify ways to avoid the post-operative complications.

\section{MATERIALS AND METHODS}

One hundred and seventeen patients who underwent thyroid surgery for various thyroid disorders at the Government Vellore Medical College Hospital, Vellore, Tamilnadu, India between January 2014 and January 2016 were studied.

Operations were performed by various professors, Assistant Professors and also by Surgical Postgraduates supervised by Senior Surgeons using various surgical techniques.

Indications for surgery in this study group include fortyfive patients with non-toxic Multinodular Goitre (MNG), twenty-two patients with toxic multinodular goitre, thirtyfour patients with nontoxic solitary nodular goitre, thirteen patients with carcinoma, two patients with recurrent goitre and one patient with colloid goitre.

of these one hundred and seven patients were female and ten patients were male.

These patients were broadly divided into two categories based on the diagnosis and treatment modality.

For all selected patients, a thorough history was elicited followed by a complete physical examination. The basic biochemical and haematological investigations were done for all patients. It was decided to request special investigations like thyroid hormone profile and serum calcium estimation only in selected cases, where a disturbance in the functional status was suspected.

Vocal cords were examined pre-operatively by indirect laryngoscope in all the patients, whereas post-operative vocal cord examination was performed only when hoarseness occurred.
Patients were classified as having hypocalcaemia (hyperparathyroidism) if both clinical and biochemical (A fall in corrected serum calcium concentration below $8 \mathrm{mg} / \mathrm{dL}$ and/or the need for calcium supplementation) supportive evidence were present.

FNAC was done for all patients. Based on the final diagnosis, the treatment was given as advised by the experts.

\section{RESULTS}

A total of one hundred and seventeen patients, aged between sixteen and sixty-one years, underwent thyroid surgery during the study period. Patients included one hundred and seven women and ten men (Females: Male, 10.7:1)

Histopathological diagnosis for each case and the number of patients undergoing each type of operation is detailed in Table 1 . Surgical morbidity associated with thyroidectomy undertaken during the study period is detailed in Table 3.

Post-operative haemorrhage occurred in four patients $(3.42 \%)$, in which three patients had total thyroidectomy $(3 / 177,2.56 \%)$ and another one patient $(0.85 \%)$ underwent bilateral subtotal thyroidectomy, of which two patients $(1.71 \%)$ required urgent re-exploration and others resolved spontaneously without drainage.

Two patients were shifted to Intensive Surgical Care Unit with endotracheal tube in situ due to respiratory difficulty $(1.71 \%)$ and both recovered well and extubated within 24 hours without any respiratory distress.

The incidence of temporary recurrent laryngeal nerve palsy was found to be one each $(0.85 \%)$ in total thyroidectomy and near total thyroidectomy, and three patients $(2.56 \%)$ in bilateral subtotal thyroidectomy. No patients in this study group developed bilateral recurrent laryngeal nerve palsy.

There were two patients $(1.71 \%)$, who underwent total thyroidectomy, developed superior laryngeal nerve paresis.

The incidence of temporary hyperparathyroidism was high at $5.98 \%$ (7) and $1.71 \%$ (2) of patients treated by total thyroidectomy and bilateral subtotal thyroidectomy respectively. Those patients who underwent hemithyroidectomy and near total thyroidectomy did not have hypoparathyroidism.

Post-operative wound infection occurred in four patients (3.42\%), of which three patients (2.56\%) underwent bilateral subtotal thyroidectomy and one patient $(0.85 \%)$ underwent hemithyroidectomy. After surgical drainage, the wound was re-sutured several days later when the infection had resolved.

Seroma occurred in one patient $(0.85 \%)$ who underwent bilateral subtotal thyroidectomy for nontoxic multinodular goitre.

Oedema of flap occurred in one patient $(0.85 \%)$ who underwent bilateral subtotal thyroidectomy for toxic goitre.

Oesophageal injury occurred in only one patient (0.85\%) who underwent bilateral subtotal thyroidectomy for nontoxic multinodular goitre. (Patient had coexistent para-pharyngeal pouch).

There were two deaths $(1.71 \%)$ noted in this series and out of which one is due to thyroid storm $(0.85 \%)$ associated with haemorrhage and respiratory obstruction in female patient who underwent bilateral subtotal thyroidectomy for toxic goitre. Another death occurred in a male patient who underwent total thyroidectomy for carcinoma thyroid. 


\begin{tabular}{|c|c|c|c|c|c|c|c|c|}
\hline Diagnosis & $\begin{array}{c}\text { Total No. } \\
\text { of Patients }\end{array}$ & $\begin{array}{l}\text { Male+ } \\
\text { Female }\end{array}$ & $\begin{array}{c}\text { Disease } \\
\text { Incidence } \\
(\%)\end{array}$ & \begin{tabular}{|c|} 
Hemi- \\
Thyroidectomy \\
(No of PTS \& \%)
\end{tabular} & \begin{tabular}{|c|} 
Bilateral \\
Subtotal \\
Thyroidectomy
\end{tabular} & \begin{tabular}{|c|} 
Near \\
Total \\
Thyroidectomy
\end{tabular} & $\begin{array}{c}\text { Total } \\
\text { Thyroidectomy }\end{array}$ & Others \\
\hline $\begin{array}{c}\text { Colloid and } \\
\text { Recurrent } \\
\text { Goitre }\end{array}$ & 3 & $1+2$ & 2.56 & - & - & - & $3(00 \%)$ & - \\
\hline $\begin{array}{l}\text { Solitary } \\
\text { Nodule }\end{array}$ & 34 & $3+31$ & 29.06 & $31(91.18 \%)$ & $3(8.82 \%)$ & - & - & - \\
\hline $\begin{array}{l}\text { Multinodular } \\
\text { Goitre }\end{array}$ & 45 & $2+43$ & 38.46 & $2(4.44 \%)$ & 40 (88.89) & $1(2.22)$ & $2(4.44)$ & - \\
\hline $\begin{array}{c}\text { Toxic Multi- } \\
\text { Nodular } \\
\text { Goitre }\end{array}$ & 22 & $3+19$ & 18.8 & - & $20(90.91)$ & - & 2 (9.09) & - \\
\hline $\begin{array}{l}\text { Thyroid } \\
\text { Cancer }\end{array}$ & 13 & $1+12$ & 11.11 & 1 & - & 1 & 10 & 1 \\
\hline Total & 117 & $\begin{array}{c}10+107 \\
(8.55 \%) \\
(91.45 \%) \\
\end{array}$ & & $\begin{array}{c}34 \\
(29.06 \%)\end{array}$ & $\begin{array}{c}63 \\
(53.85 \%)\end{array}$ & $\begin{array}{c}2 \\
(1.71 \%)\end{array}$ & $\begin{array}{c}17 \\
(14.53 \%)\end{array}$ & $\begin{array}{c}1 \\
(0.85 \%)\end{array}$ \\
\hline
\end{tabular}

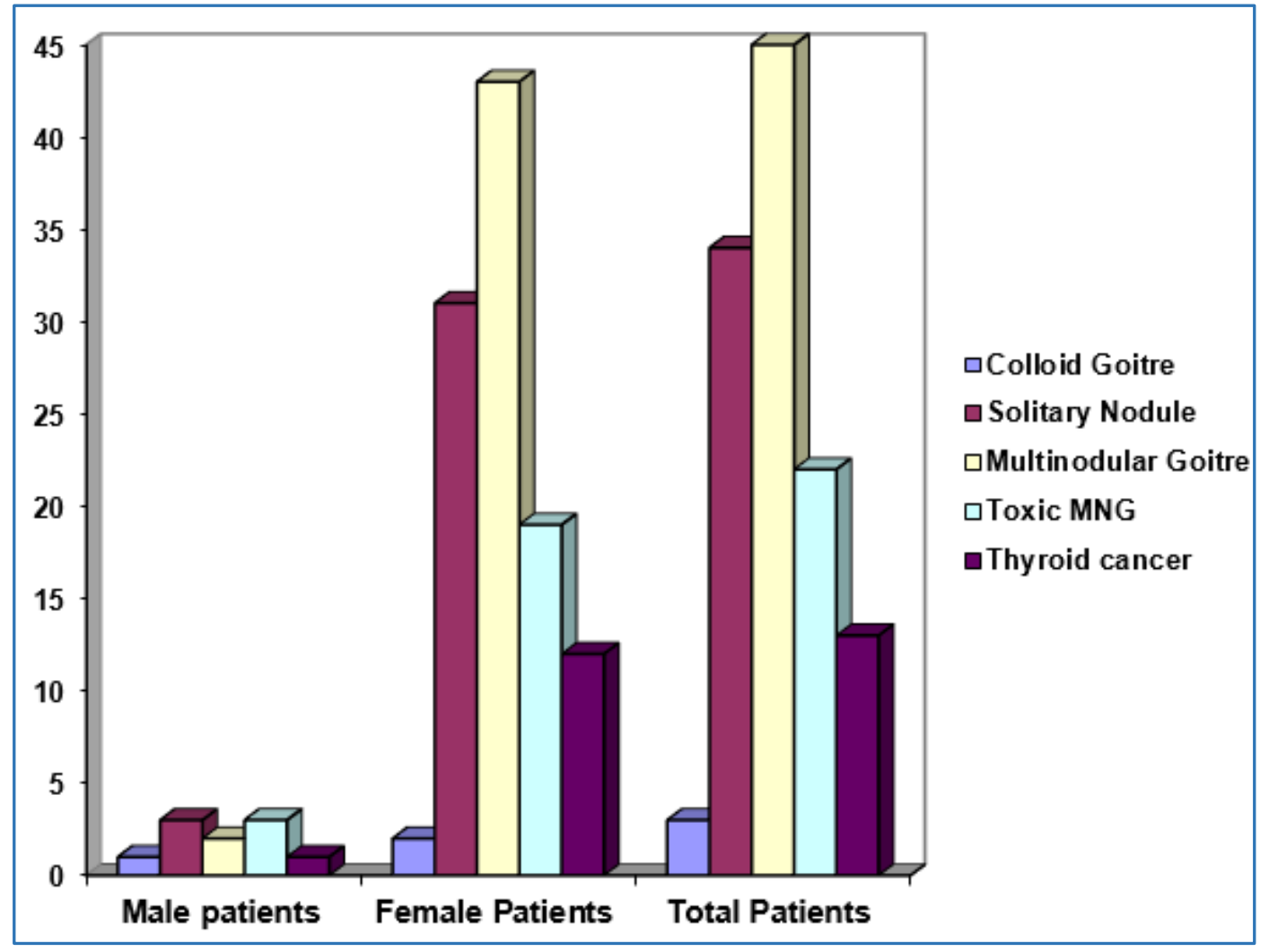

\begin{tabular}{|c|c|c|c|c|c|c|}
\hline \multirow{2}{*}{$\begin{array}{c}\text { Histological } \\
\text { Diagnosis }\end{array}$} & \multirow{2}{*}{$\begin{array}{l}\text { Total No. of } \\
\text { Patients }\end{array}$} & \multicolumn{4}{|c|}{ Number of Complications Occurred in } & \multirow{2}{*}{$\begin{array}{c}\text { Total No. of } \\
\text { Complications }\end{array}$} \\
\hline & & Hemithyroidectomy & $\begin{array}{l}\text { Bilateral } \\
\text { SBT }\end{array}$ & Near TT & $\begin{array}{c}\text { Total } \\
\text { Thyroidectomy }\end{array}$ & \\
\hline $\begin{array}{c}\text { Colloid and Recurrent } \\
\text { Goitre }\end{array}$ & 3 & - & - & - & 3 & 3 \\
\hline $\begin{array}{c}\text { Solitary Nodule } \\
\text { of Thyroid }\end{array}$ & 34 & 1 & - & - & - & 1 \\
\hline Multinodular Goitre & 45 & - & 8 & - & 3 & 11 \\
\hline $\begin{array}{l}\text { Toxic Multinodular } \\
\text { Goitre }\end{array}$ & 22 & - & 7 & - & 1 & 8 \\
\hline Thyroid Carcinoma & 13 & - & - & 1 & 8 & 9 \\
\hline Total & 117 & $1(0.85 \%)$ & $15(12.82 \%)$ & $1(0.85 \%)$ & $15(12.82 \%)$ & $32(27.35 \%)$ \\
\hline
\end{tabular}




\begin{tabular}{|c|c|c|}
\hline Sl. No. & Complications & Incidence \\
\hline 1 & Haemorrhage-Immediate & $3.42 \%(4)$ \\
\hline 2 & Respiratory Obstruction & $1.71 \%(2)$ \\
\hline 3 & Temporary Recurrent Laryngeal Nerve Palsy & $4.27 \%(5)$ \\
\hline 4 & Superior Laryngeal Nerve Palsy & $1.17 \%(2)$ \\
\hline 5 & Hypoparathyroidism-Transient & $7.69 \%(9)$ \\
\hline 6 & Thyroid Storm & $0.85 \%(1)$ \\
\hline 7 & Oedema of Flap & $0.85 \%(1)$ \\
\hline 8 & Seroma & $0.85 \%(1)$ \\
\hline 9 & Wound Infection & $3.42 \%(4)$ \\
\hline 10 & Oesophageal Injury & $0.85 \%(1)$ \\
\hline 11 & Death & $1.71 \%(2)$ \\
\hline \multicolumn{2}{|r|}{} \\
\hline
\end{tabular}

\begin{tabular}{|c|c|c|c|c|c|}
\hline Complications & Hemithyroidectomy & Bilateral SBT & Near TT & Total Thyroidectomy & Total \\
\hline Number of Patients & 34 & 63 & 2 & 17 & 117 \\
\hline Haemorrhage-Immediate & - & $1(1.59 \%)$ & - & $3(17.65 \%)$ & $4(3.42 \%)$ \\
\hline Respiratory Obstruction & - & $1(1.59 \%)$ & - & $1(5.88 \%)$ & $2(1.71 \%)$ \\
\hline Temporary Recurrent Laryngeal Nerve Palsy & - & $3(4.76 \%)$ & 1 & $1(5.88 \%)$ & $5(4.27 \%)$ \\
\hline Superior Laryngeal Nerve Palsy & - & - & - & $2(11.76 \%)$ & $2(1.71 \%)$ \\
\hline Hypoparathyroidism-Transient & - & $2(3.17 \%)$ & - & $7(41.18 \%)$ & $9(7.69 \%)$ \\
\hline Thyroid Storm & & $1(1.59 \%)$ & - & - & $1(0.85 \%)$ \\
\hline Oedema of Flap & & $1(1.59 \%)$ & - & - & $1(0.85 \%)$ \\
\hline Seroma & & $1(1.59 \%)$ & - & - & $1(0.85 \%)$ \\
\hline Wound Infection & $1(2.94 \%)$ & $3(4.76 \%)$ & - & - & $4(3.42 \%)$ \\
\hline Oesophageal Injury & & $1(1.59 \%)$ & - & - & $1(0.85 \%)$ \\
\hline Death & & $1(1.59 \%)$ & - & $1(5.88 \%)$ & $2(1.71 \%)$ \\
\hline Total & 1 & 15 & 1 & 15 & $\begin{array}{c}31 \\
(27.35 \%) \\
\end{array}$ \\
\hline
\end{tabular}

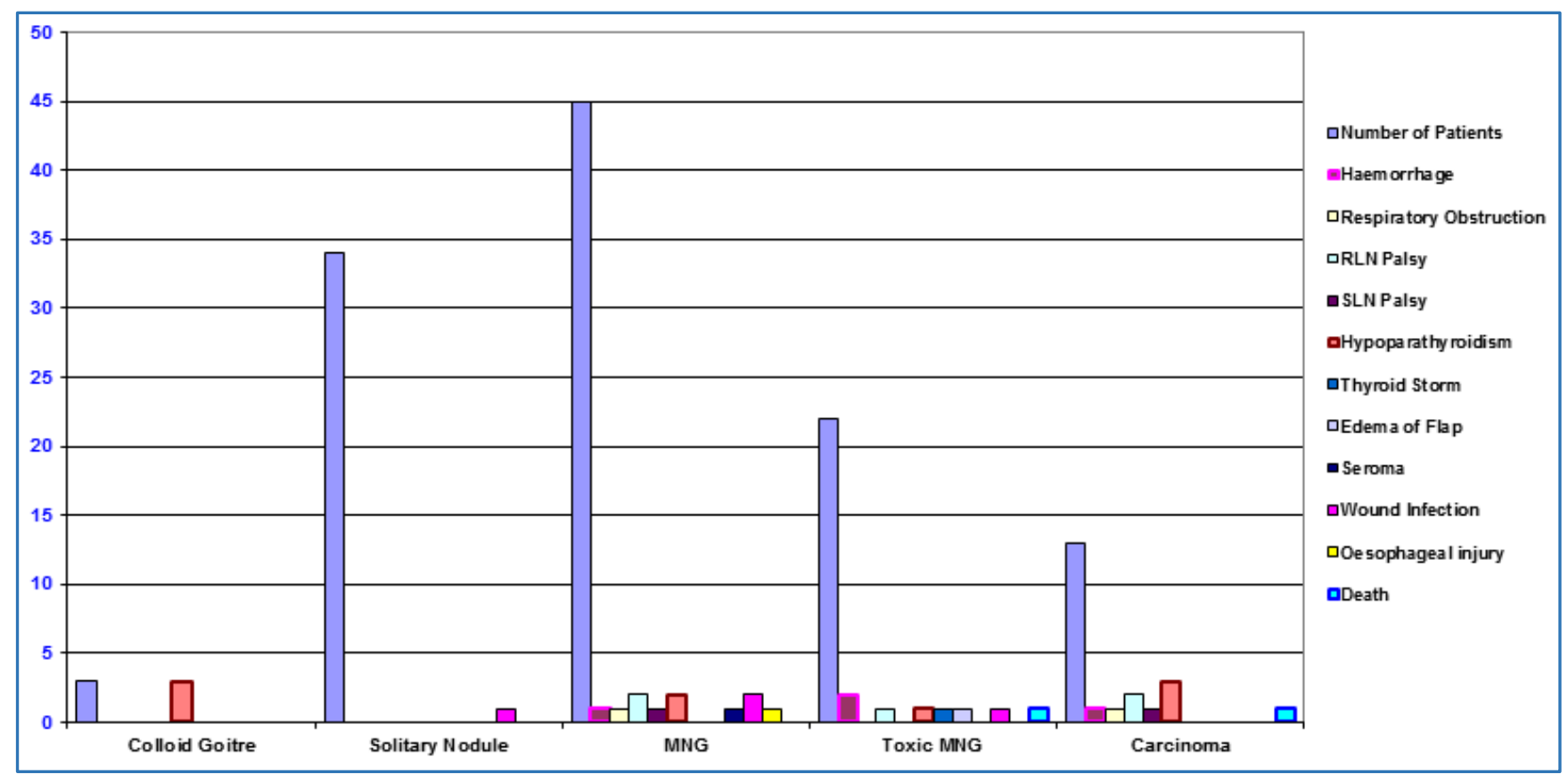

Figure 2. Complication after Thyroidectomy for Various Thyroid Disorders 


\begin{tabular}{|c|c|c|c|c|c|c|}
\hline Complications & $\begin{array}{c}\text { Colloid and } \\
\text { Recurrent } \\
\text { Goitre }\end{array}$ & $\begin{array}{l}\text { Solitary } \\
\text { Nodule }\end{array}$ & $\begin{array}{c}\text { Multi-Nodular } \\
\text { Goitre }\end{array}$ & $\begin{array}{c}\text { Toxic Multi- } \\
\text { Nodular Goitre }\end{array}$ & Carcinoma & Total \\
\hline Number of Patients & 3 & 34 & 45 & 22 & 13 & 117 \\
\hline Haemorrhage-Immediate & - & - & 1 & 2 & 1 & $4(3.42 \%)$ \\
\hline Respiratory Obstruction & - & - & 1 & - & 1 & $2(1.71 \%)$ \\
\hline $\begin{array}{l}\text { Temporary Recurrent } \\
\text { Laryngeal Nerve Palsy }\end{array}$ & - & - & 2 & 1 & 2 & $5(4.27 \%)$ \\
\hline $\begin{array}{l}\text { Superior Laryngeal } \\
\text { Nerve Palsy }\end{array}$ & - & - & 1 & - & 1 & $2(1.71 \%)$ \\
\hline $\begin{array}{c}\text { Hypoparathyroidism- } \\
\text { Transient }\end{array}$ & 3 & - & 2 & 1 & 3 & $9(7.69 \%)$ \\
\hline Thyroid Storm & - & - & - & 1 & - & $1(0.85 \%)$ \\
\hline Oedema of Flap & - & - & - & 1 & -- & $1(0.85 \%)$ \\
\hline Seroma & - & - & 1 & - & - & $1(0.85 \%)$ \\
\hline Wound Infection & - & 1 & 2 & 1 & - & $4(3.42 \%)$ \\
\hline Oesophageal Injury & - & - & 1 & - & - & $1(0.85 \%)$ \\
\hline Death & - & - & - & 1 & 1 & $2(1.71 \%)$ \\
\hline Total & 3 & 1 & 11 & 8 & 9 & $31(27.35 \%)$ \\
\hline
\end{tabular}

\begin{tabular}{|c|c|c|c|c|}
\hline \begin{tabular}{|c|c} 
Sl. \\
No
\end{tabular} & $\begin{array}{c}\text { Histopathological } \\
\text { Diagnosis }\end{array}$ & \begin{tabular}{|c|}
$\begin{array}{c}\text { Total No. } \\
\text { of } \\
\text { Patients }\end{array}$ \\
\end{tabular} & \begin{tabular}{|c|} 
Total \\
No. of \\
Complications
\end{tabular} & $\begin{array}{c}\text { Incidence } \\
\%\end{array}$ \\
\hline 1. & Benign Disorders & 104 & 23 & 22.12 \\
\hline 2. & Malignant Disease & 13 & 9 & 69.23 \\
\hline & Total & 117 & 32 & 27.35 \\
\hline
\end{tabular}

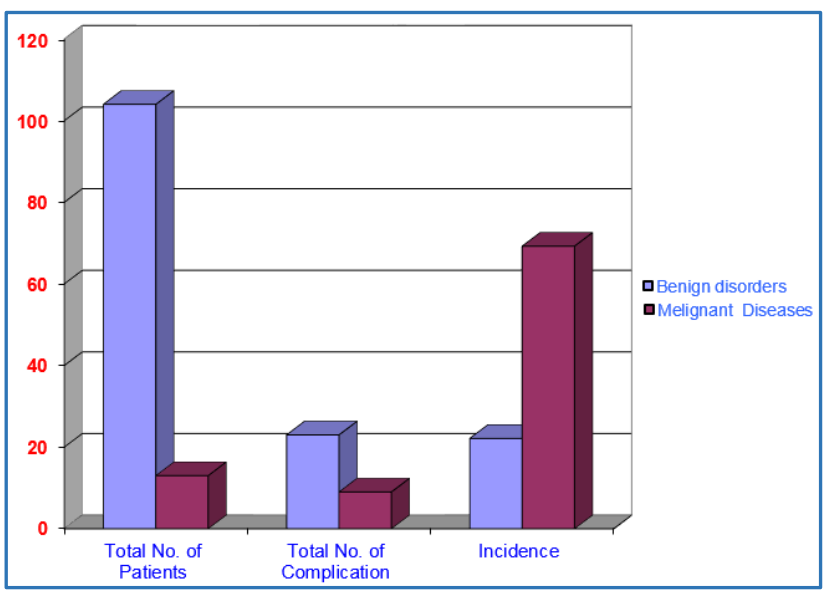

Figure 3. Comparison of Complication Rate after

Thyroidectomy for Benign and Malignant Disorders

\section{DISCUSSION}

The results in this study are in correlation with published results of similar hospitals around the world.

Haemorrhagic complications where more frequent in total thyroidectomy $(2.56 \%)$ when compared to bilateral subtotal thyroidectomy $(0.85 \%)$ when compared to the results published by Rosato $\mathrm{L}$ et al. $^{3}$ Though the haemorrhagic complication is considerably lower in bilateral subtotal thyroidectomy group (2.1\%), ${ }^{3}$ it was higher in total thyroidectomy $(1.6 \%))^{3}$ It frequently occurs during the postanaesthetic period when the end tracheal tube is removed. The prevention of post-operative bleeding is dependent on good intraoperative haemostasis. Sound surgical technique is essential.
The $4.27 \%$ incidence of recurrent laryngeal nerve (vocal cord) palsy seen in this series is in concordance with reported incidence figures $(0.1 \%-4.5 \%))^{4-7}$ Complications of thyroidectomy are largely related to the magnitude of the operation and the experience of the surgeon involved. Most thyroid operations at the Government Vellore Medical College Hospital, Vellore, are performed by senior surgeons or by advanced trainees under supervision. This may account for the desirable paucity of vocal cord palsy seen.

Every effort should be made to preserve parathyroid glands with their own blood supply; however, this may not be sufficient to prevent the occurrence of transient hypoparathyroidism and transient post-thyroidectomy hypocalcaemia, secondary to hypoparathyroidism is common. ${ }^{(8,9)}$ Delbridge et al(10) state that transient hypoparathyroidism should be an accepted outcome of bilateral thyroid surgery rather than a complication. It is noted that the degree and duration of hypocalcaemia increase with the extent of thyroid surgery.(11) Permanent hypoparathyroidism has been reported to occur after total thyroidectomy is between $0.1 \%$ and $32 \%$ of patients overall.1,2,5-7,12,13 The risk is higher for cancer surgery and ranges from 3 to $32 \%{ }^{1,2,5-7,13}$ Most published reports in the last five years, however, quote a figure below $10 \%$. Our results $(7.69 \%)$ concur with the literature with an incidence of temporary hypoparathyroidism increased with extent of surgery (Table).

The non-capsular dissection technique may be the cause for the $7.69 \%$ incidence of hypoparathyroidism, as the parathyroid gland is vulnerable to devascularisation or inadvertent removal with the thyroid gland during such a procedure. The capsular dissection technique may be useful in reducing this complication.

This study also reveals complication rate was identical to both bilateral subtotal thyroidectomy $(15 / 117,12.82 \%$; $15 / 63,23.81 \%)$ and in total thyroidectomy $(14 / 117,11.97 \%$; $14 / 17,82.35 \%)$.

The greater incidence of complications with TT is attributable mainly to the greater incidence of transient hypocalcaemia and to a lesser extent to the slightly higher 
incidence of haemorrhage, whereas the incidences of recurrent laryngeal nerve injuries were slightly higher in bilateral subtotal thyroidectomy. Incidences of other complications are also higher in bilateral subtotal thyroidectomy. Our results concur with the study report published by Rosato et al. ${ }^{3}$

Bearing in mind that total thyroidectomy is the absolute indication in the more demanding thyroid disease (Tumours, retrosternal goitre, Basedow's disease and recurrences) and in view of its fairly low complication rate; we believe that total thyroidectomy is a safe, reliable procedure, provided it is performed in a technically scrupulous manner. Bilateral subtotal thyroidectomy is a technique which should be abandoned because, its complication rate is comparable to that of total thyroidectomy and to the recurrences it may give rise to. ${ }^{3}$

This study reveals that the hemithyroidectomy is an extremely safe procedure without any complication.

This series also reveals higher incidence of complication rates after thyroidectomy for malignant thyroid disease $69.23 \%$ (9/13) than benign thyroid disease $22.12 \%$ (23/104).

Post-operative mortality has been reported to occur in between NIL to ONE percent. The highest reported incidence was $1 \%$ by Haider A et al. In contrast to most published data, the incidence of mortality in this series is $1.71 \%$ (two patients). Out of two patients one died due to an unusual complication of thyrotoxic storm. Adequate pre-operative preparation to bring the patient to euthyroid status and ten days therapy with Lugol's iodine, will eliminate this complication.

\section{CONCLUSION}

\section{The Following Conclusions are drawn from this Study}

1. This study shows that the total thyroidectomy or hemithyroidectomy can be done with very low complication rate in cases of benign thyroid disease affecting the whole gland.

2. Hypoparathyroidism, however, is a relatively common and significant complication than the recurrent laryngeal nerve injury after surgery for thyroid disorders.

3. Thyroid carcinoma, recurrent goitre, toxic goitre and total thyroidectomy are risk factors for post-operative complication.

4. Complication rates are similar for bilateral subtotal thyroidectomy and total thyroidectomy, and there is a risk of recurrence with bilateral subtotal thyroidectomy. Because total thyroidectomy carries a risk of complication similar to that for bilateral subtotal thyroidectomy, it is not logical to avoid total resections. Therefore, near total or total thyroidectomy may be the operation of choice for multinodular goitre.

5. Complications and sequelae of thyroid surgery can yet be reduced by careful evaluation of the surgical and medical therapeutic options have more precise surgical indications, a thorough knowledge of the surgical anatomy, a rigorous surgical technique, a systematic dissection of recurrent laryngeal nerve and parathyroid gland in case of bilateral operation and meticulousness during the procedure.

I conclude that the operative skills and experience determine the complication rates rather than the type of operative procedure.

\section{REFERENCES}

[1] Foster RS Jr. Morbidity and mortality after thyroidectomy. Surg Gynecol Obstet 1978;146(3):4239.

[2] Harness JK, Fung L, Thompson NW, et al. Total thyroidectomy: complications and techniques. World J Surg 1986;10(5):781-6.

[3] Rosato L, Avenia N, De Palma M, et al. Complications of total thyroidectomy: incidence, prevention and treatment. Chir Ital 2002;54(5):635-42.

[4] Chow TL, Chu W, Lim BH, et al. Outcomes and complications of thyroid surgery: retrospective study. Hong Kong Med J 2001;7(3):261-5.

[5] Hay ID, Grant CS, Taylor WF, et al. Ipsilateral lobectomy versus bilateral lobar resection in papillary thyroid carcinoma: a retrospective analysis of surgical outcome using a novel prognostic scoring system. Surgery 1987;102(6):1088-95.

[6] Wanebo H, Coburn M, Teates D, et al. Total thyroidectomy does not enhance disease control or survival even in high-risk patients with differentiated thyroid cancer. Ann Surg 1998;227(6):912-21.

[7] Tzavara I, Vlassopoulou B, Alevizaki C, et al. Differentiated thyroid cancer: a retrospective analysis of 832 cases from Greece. Clin Endocrinol (oxf) 1999;50(5):643-54.

[8] Bergamaschi R, Becouarn G, Ronceray J, et al. Morbidity of thyroid surgery. Am J Surg 1998;176(1):71-75.

[9] Pattou F, Combemale F, Fabre S, et al. Hypocalcemia following thyroid surgery: incidence and prediction of outcome. World J Surg 1998;22(7):718-24.

[10] Delbridge L, Guinea AI, Reeve TS, et al. Total thyroidectomy for bilateral benign multinodular goitre: effect of changing practice. Arch Surg 1999;134(12):1389-93.

[11] Demeester-Mirkine N, Hooghe L, Van Geertruyden J, et al. Hypocalcemia after thyroidectomy. Arch Surg 1992;127(7):854-8.

[12] Clark OH. Total thyroidectomy: the treatment of choice for patients with differentiated thyroid cancer. Ann Surg 1982;196(3):361-70.

[13] Tisell LE, Nilsson B, Molne J, et al. Improved survival of patients with papillary thyroid cancer after surgical micro dissection. World J Surg 1996;20(7):854-9. 